\title{
Moet relationeel geweld apart strafbaar worden gesteld?
}

Mw mr K.D. Lünnemann*

Dick (36 jaar) gaat samenwonen met Lianne (39 jaar). Ze krijgen een dochter.

$\mathrm{Na}$ vijf jaar te hebben samengewoond gaan ze uit elkaar, omdat Dick vaak dronken is. Hij wordt dan zeer agressief en vernielt huisraad.

Op een avond belt Dick dronken aan. Lianne doet de deur in eerste instantie niet open, maar als Dick blijft bellen wordt ze zo nerveus dat ze opendoet. Dick heeft patat en ijs meegenomen om dit samen met zijn dochtertje van drie op te eten. Het dochtertje wordt door hem uit bed gehaald en Lianne gaat koffie zetten in de hoop dat hij daardoor ontnuchtert. Dan wordt er gebeld en een vriend van hun staat op de stoep. Als Dick deze vriend ziet wordt hij zo boos dat hij met een hamer de televisie kapot slaat. Lianne belt de politie en doet aangifte van vernieling. Het schadebedrag is $f 400,-$. Lianne stelt zich als benadeelde partij.

De voorgaande casus kan als een zaak van belaging worden gedefinieerd. Op het eerste gezicht gaat het niet om ernstig geweld. Toch moet de ernst niet worden onderschat omdat het gedrag van Dick zeer onvoorspelbaar is en het agressieve gedrag wordt ervaren als een enorme inbreuk op de huisvrede en persoonlijke levenssfeer. Met dit gedrag houdt Dick Lianne in zijn macht.

Momenteel ligt er bij de Tweede Kamer een initiatiefwetsvoorstel om belaging strafbaar te stellen, zoals in de bijdrage van Remmelink uiteen is gezet. Wat dit kan betekenen voor vrouwen die belagingsslachtoffer zijn, zal ik aan het einde van dit artikel behandelen.

In deze bijdrage concentreer ik mij op de vraag of specifieke strafbaarstelling van relationeel geweld tussen volwassenen wenselijk is. Eerst zal worden ingegaan op de problematiek van relationeel geweld, vervolgens worden twee strafrechtelijke knelpunten behandeld om tenslotte op de vraag van specifieke strafbaarstelling in te gaan.

* Verbonden aan de Faculteit der Rechtsgeleerdheid bij de discipline ICEP van de Univer-siteit Utrecht. 
Voor de duidelijkheid: relationeel geweld tegen vrouwen vat ik op als geweld of bedreiging met geweld tegen de vrouw door haar partner of ex-partner. Ik focus op het geweld tegen vrouwen. Dat wil niet zeggen dat er binnen heterosexuele relaties geen geweld tegen de man plaatsvindt. Op individueel niveau kan het geweld even ernstig zijn, maar maatschappelijk gezien zijn met name vrouwen slachtoffer van ernstig eenzijdig geweld en alleen vrouwen zijn slachtoffer van seksueel geweld. ${ }^{1}$ Vandaar dat ik het vooral over vrouwenmishandeling zal hebben. ${ }^{2}$

\section{Vrouwenmishandeling}

Eind jaren tachtig heb ik dossiers onderzocht op de arrondissementsparketten Assen, Breda en Rotterdam. Meer dan duizend geweldszaken trokken aan mij voorbij, van eenvoudige mishandeling en bedreiging via allerlei ernstige geweldszaken en pogingen tot doodslag en moord, tot ernstige zaken van seksuele dwang. Van al die geweldszaken heb ik 150 zaken van mannelijk geweld tegen de vrouw in de privésfeer nader geanalyseerd. ${ }^{3}$ Uit deze dossieranalyse blijkt dat een grote variëteit aan zaken van vrouwenmishandeling het arrondissementsparket bereikt, zowel wat betreft de ernst van de mishandeling als wat betreft de relatie waarin de vrouwen zich bevinden. Het letsel varieert bijvoorbeeld van een blauwe plek tot zeer ernstig letsel en de vernielingen van een gebroken ruitje tot een grote ravage in huis. De relaties variëren van een jarenlang huwelijk tot een LAT-relatie en van net gescheiden tot lang geleden gescheiden.

Naar aanleiding van de gesprekken met officieren van justitie komt het beeld naar voren dat het geweld wordt gepleegd door gelijkwaardige partners, terwijl beiden evenveel verantwoordelijkheid daarvoor dragen. ${ }^{4} \mathrm{Nu}$ zijn er zeker gevallen van relationeel geweld waarbij man en vrouw beiden verantwoordelijk zijn voor het geweld en waarin gesproken kan worden van een symbiotische en destructieve relatie. Bijvoorbeeld als beiden alcoholist of psychisch zeer onstabiel zijn. Er kan sprake zijn van een zekere mate van ontoerekeningsvatbaarheid.

1 R. Römkens, Gewoon geweld? omvang, aard, gevolgen en achtergronden van geweld tegen vrouwen in heteroseksuele relaties, Swets \& Zeitlinger, Amsterdam \& Lisse 1992.

2 Geweld in homosexuele relaties laat ik eveneens buiten beschouwing.

3 Per arrondissementsparket zijn 50 dossiers nader geanalyseerd. Lünnemann, Vrouwenmishandeling strafrechtelijk afgedaan? 1996, hoofdstuk 5, p. 147-206.

4 Zie bijvoorbeeld ook: B.G.T.J. ter Heine, Gewelddadigheid in huwelijk en gezin, een forensisch-psychologische bijdrage, DD, 1995, p. 943-955. 
Maar veruit de meerderheid van de zaken die ik heb onderzocht betroffen geweld door gewone, gezonde, toerekeningsvatbare mannen.

Er zijn drie karakteristieken die vrouwenmishandeling onderscheiden van ander geweld. Allereerst de emotionele en sociale binding tussen pleger en slachtoffer. Van belang is te onderkennen dat de hand die slaat ook de hand is die liefkoost. Naast het geweld en de vernederingen zijn er momenten van liefde, vertrouwdheid en gezamenlijke sociale contacten. Vaak zijn er kinderen en is de vrouw sociaal en economisch afhankelijk van de man. Het geweld dat wordt gebruikt bevestigt de dominantie van de man, mede omdat vrouwen geneigd zijn de verantwoordelijkheid voor het geweld op zich te nemen. Dit versterkt de afhankelijkheid van elkaar. ${ }^{5}$

Een tweede karakteristiek is dat sprake is van herhaald en ernstig geweld tegen een achtergrond van permanente dreiging en angst. Ook in het voorbeeld aan het begin van mijn verhaal creëert Dick door zijn gedrag een sfeer van bedreiging en angst, mede omdat zijn gedrag onvoorspelbaar is. Permanent aanwezige dreiging en angst kunnen ernstige depressieve en psychosomatische klachten bij de vrouw tot gevolg hebben.

Als derde karakteristiek geldt het isolement waarin de vrouw zit. Het geweld wordt zo goed mogelijk geheim gehouden voor de buitenwereld. De privacy van de samenlevingsvorm betekent hier geheimhouding. ${ }^{6}$ Mede door dit isolement ontbreekt een veilige omgeving. Terwijl een veilige omgeving nodig is om te kunnen herstellen van de negatieve gevolgen van het gepleegde geweld. ${ }^{7}$ In deze geweldsspiraal kan een proces van 'traumatische binding' in gang worden gezet. ${ }^{8}$ Door verschillen in macht binnen de relatie, de afwisseling van goede en slechte perioden waar de vrouw geen invloed op heeft, en het isolement waar de partners in zitten wordt een sterke negatieve emotionele binding gecreëerd. De weerbaarheid en het zelfvertrouwen van de vrouw kunnen er sterk door zijn aangetast. Dit wil overigens niet zeggen dat de vrouw helemaal geen invloed heeft en willoos slachtoffer is, maar er is geen sprake van een gelijkwaardige relatie.

Deze drie aspecten, - de emotionele en sociaal-economische binding, herhaald geweld tegen de achtergrond van dreiging en angst en het isolement -, bepalen het specifieke karakter van vrouwenmishandeling. Een veilige omgeving ontbreekt. Geweld tegen vrouwen in de relationele sfeer onderscheidt zich dan

5 R. Römkens, Het onbehagen over geweld tegen vrouwen, projectie en internalisering van verantwoordelijkheid en schuld, in: P.B. Defares \& J.D. van de Ploeg (red.), Agressie. Determinanten, signalering en interventie, Van Gorcum, Assen \& Maastricht 1991, p. 211-227.

6 E.M. Schneider, The violence of privacy, in: M.A. Fineman \& R. Mykitiuk (eds), The public nature of private violence: the discovery of domestic abuse, Routledge, New York/London 1994: 36-58.

7 J.L. Herman, Trauma en herstel: de gevolgen van geweld, van mishandeling thuis tot politiek geweld, Wereldbibliotheek, Amsterdam 1993.

8 D. Dutton \& S.L. Painter, Traumatic bonding: the development of emotional attachments in battered women and other relationships of intermittent abuse, Victimology: an international journal, 1981, jrg. 6, nr. 1, p. 139-155. 
ook van ander geweld, niet zozeer door de gedraging, maar vooral door de context waarin het geweld plaatsvindt. 


\section{Twee belangrijke strafrechtelijke knelpunten}

Het belangrijkste doel van strafrechtelijk optreden als het gaat om geweld tegen vrouwen in de huiselijke sfeer is het voorkomen van recidive, gezien de grote kans op herhaling van het geweld. Daarnaast kan genoegdoening of conflictoplossing als doel gesteld worden. Ik zal nu niet ingaan op de knelpunten op het niveau van politie en openbaar ministerie, maar mij concentreren de juridische knelpunten. Dit zijn de onzichtbaarheid van de problematiek in het materiële strafrecht en het ontbreken van de bevoegdheid tot inverzekeringstelling.

\section{Onzichtbaarheid in het materiële recht}

Vrouwenmishandeling wordt vaak casuïstisch benaderd, niet als relevant juridisch probleem. Het geweld dat wordt gepleegd valt onder verschillende strafbepalingen, zoals mishandeling, zware mishandeling, bedreiging, doodslag, verkrachting, aanranding en huisvredebreuk. Agressief gedrag kan ook als vernieling worden gekwalificeerd. Als je kijkt naar hoe de verschillende delictsbepalingen worden geïnterpreteerd, valt op dat de specifieke ernst van geweld in de privésfeer niet, of niet altijd, door de delictsomschrijving wordt gedekt.

De vernielingen kunnen gericht zijn op het kwetsen van de vrouw, bijvoorbeeld door spullen te vernielen die haar zeer dierbaar zijn. Vernielingen kunnen ook zeer bedreigend zijn, zoals het gooien met een barkruk. Het te beschermen belang van vernieling $(350 \mathrm{Sr})$ is het ongestoord gebruik van het goed, terwijl in geval van vrouwenmishandeling de inbreuk op de persoonlijke vrijheid de essentie van vernieling is. Bovendien zijn diefstal en vernieling uitgesloten van strafvervolging als dit binnen echt plaatsvindt (art. $353 \mathrm{Sr}$ ). Dit kan schrijnende taferelen opleveren, zeker in de periode dat de vrouw de echtscheiding heeft aangevraagd en er nog geen voorlopige voorziening ligt. Juist in tijden van het verbreken van de relatie is de kans op escalatie, waaronder vernieling en meenemen van goederen uit het gezamenlijke huis, erg groot.

9 Zie hierover: D.W. van der Ent \& Th.D. Evers, Vrouwenmishandeling: een zorg voor de politie, Politie Regio Utrecht 1996; O.J. Zoomer, Vrouwenmishandeling; politiewerk, Gouda Quint, Arnhem 1990; M. Wöstmann, Politieoptreden bij vrouwenmishandeling, Van den Brink \& Co, Lochem 1988. 
Bij huisvredebreuk $(138 \mathrm{Sr})$ gaat het om bescherming van het intieme private leven, het huisrecht. Het probleem zit hier niet in het te beschermen belang, maar in het bewijs van de bestanddelen 'binnendringen' en 'wederrechtelijk'. Als na lang aanbellen en schreeuwen door de man de vrouw uiteindelijk de deur opendoet omdat ze weet dat hij anders heel agressief wordt, is er juridisch beschouwd geen sprake van huisvredebreuk, terwijl er wel degelijk een inbreuk op haar huissfeer wordt gemaakt. Naar omstandigheden kunnen overigens de bedreigingen die worden geuit als bedreigingen in de zin van artikel 138 lid $3 \mathrm{Sr}$ worden opgevat. ${ }^{10}$

In geval van mishandeling (300-304 Sr) zijn de twee belangrijkste problemen het bewijs van opzet en het ernstoordeel. Meestal wordt uit de gedraging het opzet afgeleid, zoals bij schoppen, slaan, bijten, of brandende sigaretten in de huid drukken. Maar bij duwen en aangrijpen kan minder snel het opzet om leed of letsel toe te brengen worden afgeleid van de gedraging. Dit is mede afhankelijk van hoe de feiten worden geïnterpreteerd. Bijvoorbeeld in het geval dat de vrouw naar het huis van haar ex-partner gaat omdat zij geld van hem krijgt. Na aanbellen wordt zij opgepakt en op de grond geduwd. De man stelt dat hij zijn ex-vrouw weliswaar tegen de grond heeft geduwd, maar geen opzet had haar pijn te doen; hij wilde haar enkel verwijderen. Dit verweer kan worden opgevat als het ontbreken van opzet, maar ook kan geoordeeld worden dat het opzet op pijn bewezen is verklaard. Hierbij is van belang of de gedraging wordt geplaatst in de context van eerder geweld en dominantiegedrag van de man of dat het gedrag wordt beschouwd als een incident tussen twee gelijkwaardige en emotionele mensen.

10 Uit het dossieronderzoek komt naar voren dat bij ongewenste aanwezigheid van de ex-partner strak wordt vastgehouden aan de regel dat de vrouw twee keer moet zeggen dat de man zich moet verwijderen. Als de vrouw zo van streek is dat zij dit niet doet, wordt geen huisvredebreuk aangenomen. Dit lijkt op een sterk doorgevoerd formalisme.

44 
Ditzelfde geldt voor het oordeel over de ernst van het letsel. Als het letsel op zichzelf wordt beoordeeld, is er doorgaans sprake van niet al te ernstig letsel, zoals blauwe plekken en kneuzingen of ernstiger letsel dat niet als zware mishandeling kan worden gekwalificeerd, zoals wonden of gebroken tanden. Wanneer dit letsel wordt geplaatst in de context van herhaald geweld, bedreigingen en angst, dan zijn die blauwe plekken ernstiger dan de uitdrukking 'droge klap' doen vermoeden. En de ernstige vormen van letsel staan, zeker gezien de context waarin dit geweld plaatsvindt, niet in verhouding tot het oordeel 'eenvoudige mishandeling'. Bovendien valt onder mishandeling regelmatig de wurgpoging die niet heeft geresulteerd in een beschadigd strottehoofd en waarvan het opzet te doden niet bewezen wordt verklaard. Een voltooide wurging kan als mishandeling met de dood tot gevolg worden gekwalificeerd. De wurgpoging is een veelvoorkomende manier van geweldpleging in geval van vrouwenmishandeling. Dit komt uit literatuur ${ }^{11}$ naar voren en eveneens uit mijn dossieronderzoek. $^{12}$ Juist de opzetconstructie is mede afhankelijk van het perspectief op grond waarvan de feiten en omstandigheden worden beoordeeld. Wanneer het geweld en de poging de vrouw te wurgen worden beoordeeld vanuit het perspectief dat twee gelijkwaardige mensen een relationeel conflict hebben en het agressieve gedrag wordt beschouwd als een wanhoopsdaad, als een emotionele uitbarsting, zal de poging tot doodslag niet snel bewezen worden verklaard. $^{13}$

Nog een enkele opmerking over de interpretatie van dwang als het gaat om verkrachting binnen een relatie of door de ex-partner. Het verkrachtingsarrest van HR 16 juni 1987 (NJ 1988, 156), waar toentertijd zoveel ophef over is geweest, kan worden beschouwd als een voorbeeld van een vrouwenmishandelingszaak waarin de dwang niet bewezen werd verklaard, omdat uitgegaan werd van een gelijkwaardige relatie. De casus betrof, kort gezegd, een relatie die in het dominante betoog wordt aangeduid als een knipperlichtrelatie, als een proces van aantrekken en afstoten. Als je de feiten leest ontstaat een ander beeld, namelijk dat de vrouw probeert aan de man te ontsnappen door de relatie te verbreken, door te verhuizen, en door het adres geheim te houden. De man weet haar echter telkens weer te vinden. ${ }^{14}$ De verkrachting staat in deze zaak niet op zichzelf, maar past in een patroon van de vrouw lastig vallen, bedreigen en

11 Voor Nederland, zie: Römkens, Gewoon geweld? 1992, p. 119.

12 In één vijfde van de mishandelingszaken komt een wurgpoging voor. Van de 9 zaken die een poging tot doodslag betroffen werd in 7 gevallen ook een poging tot wurgen gedaan. De twee gedode vrouwen uit mijn onderzoek zijn door wurging om het leven gekomen.

13 Hoewel de strafverzwarende bepaling van artikel $304 \mathrm{Sr}$ aangeeft dat de piëteit ten opzichte van naaste verwanten een zwaardere straf rechtvaardigt, blijkt in de rechtspraktijk dit artikel min of meer een dode letter te zijn. Bovendien doet de strafverzwarende bepaling geen recht aan de verschillende vormen van relationeel geweld, noch aan de andere samenlevingsvormen (ook niet na aanvulling met geregistreerd partnerschap), noch aan het feit dat geweld in de privésfeer als een specifieke aantasting van de persoonlijke vrijheid kan worden beschouwd.

14 Het arrest wordt uitgebreid besproken in: P.J. Baauw, Zuivere verkrachting? Ars Aequi, 1988, jrg. 37, nr. 9, p. 575-586. 
geweld plegen. De overtuiging of sprake is van voldoende bewijs wordt mede beïnvloed door de vooronderstelling dat seksualiteit een wezenlijk aspect is van een intieme relatie. De vraag of de vrouw de relatie definitief heeft verbroken, is zodoende van invloed op de overtuiging. Vanuit het idee dat seksualiteit een kwestie is van geven en nemen tussen twee volwassenen die vrijwillig met elkaar een relatie zijn aangegaan, wordt de manier waarop de man zijn seksuele lusten opdringt en afdwingt minder snel als dwang beschouwd dan wanneer het gedrag van de man tegen de achtergrond van dominantie en geweldpleging wordt beschouwd. Beide perspectieven zijn overigens terug te vinden in uitspraken over verkrachting.

De problematiek van seksuele dwang binnen relaties is zeer complex en de vraag hoe de vooronderstelling van gewenste seksualiteit binnen intieme relaties van invloed is op de beoordeling of sprake is van dwang is niet makkelijk te beantwoorden. Duidelijk is echter dat in het proces van waarheidsvinding het perspectief van waaruit feiten worden onderscheiden als relevant of niet relevant van groot belang is voor de overtuiging en de waardering van de ernst van de feiten. Dit geldt overigens niet alleen voor zaken van seksuele dwang binnen intieme relaties, maar voor alle vormen van relationeel geweld.

Concluderend: De huidige onderverdeling in titels in het wetboek van strafrecht lijkt niet aan te sluiten bij het specifieke karakter van relationeel geweld. Het uitoefenen van agressie door spullen te vernielen kan eerder worden beschouwd als aantasting van de persoonlijke vrijheid (titel XXVII) en dit geldt ook voor huisvredebreuk, een delict dat nu als inbreuk op de openbare orde staat geformuleerd (titel V). Bovendien blijkt dat de ernst van het geweld vaak niet wordt onderkend doordat uitgegaan wordt van gelijkwaardigheid en niet van dominerend en controlerend gedrag van de man. Dit perspectief is mede van invloed op de constructie van de opzet; er wordt sneller uitgegaan van een emotionele uitbarsting dan van bewuste agressiviteit. Het is daarom nodig de delictomschrijvingen opnieuw te doordenken vanuit de idee dat vrouwen als burger recht hebben op lichamelijke integriteit, seksuele zelfbeschikking en een persoonlijke levenssfeer binnen de privésfeer.

Het ontbreken van de bevoegdheid tot inverzekeringstelling

Het tweede knelpunt is van strafprocesrechtelijke aard. In geval van vrouwenmishandeling gaat het vaak om zogenaamde eenvoudige delicten. Dit betekent dat de politie de bevoegdheid ontbeert om in crisissituaties de man in verzekering te stellen. $\mathrm{Nu}$ is er vaak wel een bedreiging of een poging tot ernstige mishandeling of doodslag te construeren, bijvoorbeeld als de man schreeuwt: 'Tk vermoord de kinderen als je een echtscheiding aanvraagt'. Eveneens kan uit eerder geweld de ernst van de bedreiging worden afgeleid. De vraag is echter of de feiten en omstandigheden voldoende aanknopingspunten bieden om met enige creativiteit bedreiging of een ernstig misdrijf te construeren, óf dat juridisch beschouwd de bevoegdheid zodanig wordt opgerekt dat hierdoor misbruik van bevoegdheid ontstaat. Bovendien is de bevoegdheid tot inverzeke- 
ringstelling er met het doel van de waarheidsvinding en niet om de vrouw veiligheid te bieden. Dit laatste is meer een bijkomend positief punt voor de vrouw. In de eerste plaats zal de inverzekeringstelling in het belang van het onderzoek moeten zijn.

Je kunt hier een vergelijking met het initiatiefwetsvoorstel belaging trekken. Daarin wordt voorgesteld de bevoegdheid tot inverzekeringstelling aan belaging te koppelen, door belaging toe te voegen aan artikel $67 \mathrm{~Sv}$. Dit wordt beargumenteerd met de wens direct veiligheid te bieden en tijdelijk rust te creëren voor het slachtoffer in situaties van crisis. Bovendien wordt erop gewezen dat dit een signaal afgeeft, dat de maatschappij belaging zeer afkeurenswaardig en strafwaardig vindt. Het probleem blijft dat inverzekeringstelling in het belang van het onderzoek moet zijn en niet in de eerste plaats een ordemaatregel is.

De onzichtbaarheid van geweld tegen vrouwen in de privésfeer in het materiële recht en het ontbreken van de bevoegdheid buiten heterdaad de man mee te nemen naar het politiebureau als sprake is van een eenvoudig misdrijf dragen eraan bij dat vrouwen niet de rechtsbescherming krijgen die ze, gezien de ernst van de problematiek, zouden moeten krijgen. Is specifieke strafbaarstelling noodzakelijk om deze knelpunten op te lossen?

\section{Aparte strafbaarstelling van geweld in de privésfeer?}

Een koppeling aan de discussie over strafbaarstelling van belaging is hier relevant. Belaging is een vorm van geweld die sterk verwant is aan de problematiek van relationeel geweld. Ook hier gaat het om herhaald geweld, vaak zijn de incidenten niet ernstig, maar door het stelselmatige en onvoorspelbare karakter kan gesproken worden van een ernstige inbreuk op de persoonlijke vrijheid van het slachtoffer. Het merendeel van de belagingszaken (gesproken wordt van $80 \%$ ) bestaat uit ex-partners die niet kunnen accepteren dat de vrouw de relatie heeft verbroken.

In de discussie over dit initiatiefwetsvoorstel binnen de Vaste Commissie van Justitie komen vragen aan de orde die eveneens gelden voor de discussie of relationeel geweld specifiek strafbaar moet worden gesteld, namelijk: het doel van strafbaarstelling is vooral het bieden van rust en veiligheid aan het slachtoffer, maar is het strafrecht hier wel voor? Is er wel een voldoende maatschappelijk belang, met andere woorden, behoort het probleem niet via het burgerlijk recht te worden aangepakt? Wordt de problematiek niet al voldoende beschermd door de huidige delictsomschrijvingen? Is een nieuwe delictsomschrijving wel voldoende uitvoerbaar en handhaafbaar? Wordt het onderliggende probleem wel doeltreffend aangepakt? ${ }^{15}$

16 TK 25.768, nr. 6. 
Het maatschappelijke belang van een strafrechtelijke aanpak van relationeel geweld heb ik hiervoor aangegeven. ${ }^{16}$ Geweld in de privésfeer is weliswaar een onderwerp dat het wetboek van strafrecht pretendeert te regelen, maar omdat geweld in de privésfeer nauwelijks onderdeel uitmaakt van het juridische debat gaat er geen symboolwerking uit van de verschillende strafbepalingen waar geweld tegen vrouwen in de privésfeer onder kan vallen. Symboolwerking betekent dat de burger weet dat geweld in de privésfeer strafbaar is gesteld en dat degenen die de wet interpreteren en uitvoeren de strafbepaling als oriëntatiepunt nemen. ${ }^{17}$ Artikel 304 Sr ontbeert bijvoorbeeld symboolwerking. De norm die ermee wordt gesteld - piëteit tegenover naaste verwanten rechtvaardigt een zwaardere straf - wordt niet als oriëntatiepunt genomen. Op het aspect van de uitvoerbaarheid kom ik straks te spreken. Eerst iets over de strafbaarstelling zelf.

17 De maatschappelijke kosten, zoals medische kosten en kosten op het terrein van hulpverlening, politie en justitie wordt jaarlijks geschat op 332,6 miljoen. D.J. Korf e.a., Economische kosten van thuisgeweld tegen vrouwen, Criminologisch Instituut Bonger 1997.

18 W.J. Witteveen, Evenwicht van machten, W.E.J. Tjeenk Willink, Zwolle 1991.

48 
Ik bepleit strafbaarstelling door het invoeren van een aparte titel in het wetboek van strafrecht, waarin niet alleen relationeel geweld tegen volwassenen, maar ook geweld tegen kinderen ondergebracht wordt. Te denken valt ook aan een bijzondere wet, waar strafrechtelijke en civielrechtelijke aspecten samen in geregeld worden. ${ }^{18}$ Hiermee wordt aangegeven dat geweld in de privésfeer een specifieke geweldsproblematiek is: de problematiek wordt zichtbaar en juridisch relevant gemaakt. Het te beschermen belang is aantasting van de persoonlijke vrijheid binnen de privésfeer. Dit belang wordt door de huidige strafwetgeving onvoldoende beschermd. Door een aparte titel of bijzondere wet zal een juridisch-dogmatische interpretatie van relationeel geweld worden ontwikkeld. Bovendien wordt de afkeuring van geweld in de privésfeer ermee tot uitdrukking gebracht, zowel van geweld in bestaande relaties, als van privacyschendend (belagend) gedrag door de ex-partner, als van mishandeling van kinderen. ${ }^{19}$ Een belangrijk strafprocessueel voordeel van een aparte titel of bijzondere wet is dat de mogelijkheid tot inverzekeringstelling aan deze strafbaarstelling kan worden gekoppeld, zoals dat ook in geval van belaging is voorgesteld. Het optreden van de politie moet zijn gericht op normstelling en op het voorkomen van recidive. Wanneer gekozen wordt voor een bijzondere wet kan bijvoorbeeld een bevoegdheid tot uithuisplaatsing in plaats van inverzekeringstelling worden geformuleerd. ${ }^{20}$ De mogelijkheid voor de politie om strafrechtelijk op te treden voor deze specifieke geweldsproblematiek wordt daarmee vergroot. ${ }^{21}$ Een

19 In Europa en de Verenigde Staten zijn in tal van landen specifieke wetten 'Domestic violence' tot stand gekomen, waar civielrechtelijke maatregelen worden ondersteund met strafrechtelijke bevoegdheden.

20 Als bijkomend effect zal het niet vervolgbaar zijn van vernieling, diefstal en afpersing door de echtgenoot worden afgeschaft en het huidige artikel $304 \mathrm{Sr}$ kan wat betreft mishandeling door verwanten vervallen.

21 Deze bevoegdheid zie je ook in de verschillende Domestic Violence Acts. De bevoegdheid tot uithuisplaatsing heeft als voordeel dat de bevoegdheid van inverzekeringstelling niet wordt misbruikt voor een ander doel.

22 De man meenemen naar het politiebureau zonder adequate vervolgreactie in de zin van een aanpak gericht op het stoppen van het geweld, voorkomt op de wat langere termijn herhaling van geweld niet. Dit blijkt uit onderzoek in de Verenigde Staten: 
argument van geheel andere orde is dat door een aparte strafbaarstelling de zichtbaarheid van deze specifieke problematiek binnen de strafrechtstatistiek wordt vergroot. Dit kan het inzicht in de strafrechtelijke aanpak van relationeel geweld vergroten en daarop kan een eventuele bijstelling van het beleid worden gebaseerd. Bovendien kan strafbaarstelling de discussie over de maatschappelijke ernst van dit specifieke geweld stimuleren, zoals naar aanleiding van initiatiefwetsvoorstel Belaging is gebeurd.

Naast de voordelen zijn twee belangrijke nadelen te noemen. Ten eerste: Is een titel in het wetboek van strafrecht of een bijzondere wet technisch wel goed uitvoerbaar? En ten tweede: Wat doen we met het gevaar van symboolwetgeving, het probleem van de handhaafbaarheid?

Wat de technische uitvoerbaarheid betreft: Hoe moet bijvoorbeeld het relationele aspect worden geformuleerd? De term intieme relatie is niet voldoende feitelijk voor een strafbepaling en zal daarom moeten worden teruggebracht tot 'een (gewezen) huwelijkse of samenwoningsrelatie'. Een LAT-relatie of een 'verkering' zullen buiten de definitie vallen, omdat de vaststelling van deze intieme relaties gepaard kan gaan met een te grote inbreuk op de persoonlijke levenssfeer van verdachte en slachtoffer. Een ander reductieprobleem doet zich voor in de omschrijving van het geweld dat strafbaar is. Gekozen zal moeten worden welke geweldsdelicten binnen de privésfeer aparte strafbaarstelling behoeven. Eveneens moet worden gekozen tussen een strafverzwarende bepaling analoog aan artikel $304 \mathrm{Sr}$ of voor elk geweldsmisdrijf een aparte strafbepaling. Welke oplossing ook wordt gekozen, er vindt een transformatie plaats van een maatschappelijke problematiek naar een juridisch hanteerbare problematiek. Dit wordt ook wel het juridiseringsdilemma genoemd. De voorkeur voor sekseneutrale wetgeving speelt hierbij eveneens een rol. Strafbaarstelling van alleen relationeel geweld tegen vrouwen maakt het sekse-specifieke aspect van huiselijk geweld weliswaar zichtbaar, maar daarmee zouden op individueel niveau mensen worden buitengesloten van speciale rechtsbescherming. Dit laatste is ongewenst en in strijd met het gelijkheidsbeginsel. De kunst zal daarom zijn het seksespecifieke aspect dat samenhangt met machtsverschillen te integreren in de uitvoering van de sekseneutrale wet.

arrestatie heeft op lange termijn alleen zin heeft als de man verplicht wordt een of andere vorm van dadertherapie te volgen. Te denken valt ook aan een verplicht contact met de reclassering gericht op het stoppen van het geweld. D.G. Dutton, The domestic assault of women: Psychological and criminal justice perspectives, UBPPress, Vancouver 1995. 
Het gevaar van symboolwetgeving ligt op de loer als er naast strafbaarstelling geen plan van aanpak van de grond komt. Begeleidende maatregelen op het terrein van de uitvoering zijn noodzakelijk om te voorkomen dat de common sense ideeën over geweld tegen vrouwen de uitvoering van de strafwet negatief beinvloeden. Het voorstel belaging strafbaar te stellen kan als voorbeeld dienen. Slachtoffers van belaging zijn in overgrote meerderheid vrouwen. De strafbaarstelling van belaging is sekseneutraal. Het relationele conflict wordt doorgaans opgevat als een emotionele aangelegenheid waarin man en vrouw een evengroot aandeel in hebben en niet als een vorm van belaging. Bovendien levert het vereiste dat sprake moet zijn van een ex-relatie een extra drempel op. Want hoewel onder belaging op grond van de delictsomschrijving zowel geweld door de partner als privacy-schendend gedrag van de ex-partner kan vallen, wordt in de memorie van toelichting alleen ingegaan op belaging door ex-partners. Dit onderscheid is overigens problematisch. Niet alleen vertoont het geweld gepleegd tijdens de relatie veel overeenkomsten met het geweld door de expartner, bovendien is in de praktijk geen duidelijke scheidslijn te trekken tussen het hebben van een intieme relatie en het gescheiden zijn. De kans is groot dat herhaalde inbreuken op de persoonlijke levenssfeer niet worden herkend als belaging in situaties waarin nog enig vrijwillig of afgedwongen contact is tussen de man en de vrouw. Het feit dat sprake is van contact wordt dan geïnterpreteerd als het hebben van een relatie. Juridisch beschouwd levert het feit dat alleen expartners kunnen belagen rechtsongelijkheid op tussen vrouwen die slachtoffer zijn van belaging door hun ex-partner en vrouwen die slachtoffer zijn van geweld door hun partner, omdat in het laatste geval de bevoegdheid tot inverzekeringstelling doorgaans ontbreekt. ${ }^{22}$

\section{Een wet met symboolwerking}

Een nieuwe delictsomschrijving die belaging strafbaar stelt, kan voor vrouwen die stelselmatig door hun ex-partner worden lastig gevallen een uitkomst bieden, als naast wetgeving een richtlijn wordt opgesteld en begeleidende maatregelen worden genomen. Voor vrouwen die geweld ondervinden binnen hun relatie blijven de knelpunten bestaan. Wetgeving blijft wenselijk.

Door relationeel geweld specifiek strafbaar te stellen worden de feiten die samenhangen met het relationele geweld niet als toevallige casuïstiek terzijde geschoven, maar als relevante feiten in het juridische vertoog naar voren gehaald. Het te beschermen belang - de persoonlijke vrijheid binnen de privésfeer - wordt uitdrukkelijk vastgelegd. Om de kans te vergroten dat het een wet met symboolwerking zal zijn en niet een louter symbolische wet, is het

22 Een ander nadelig aspect voor vrouwen is het klachtvereiste. Juist omdat de vrouw zeggenschap heeft over het voorkomen van vervolging, biedt dit klachtvereiste een aanknopingspunt voor de man om haar te bedreigen en chanteren. Uit onderzoek blijkt telkens weer dat mannen die hun vrouw of vriendin niet los kunnen laten, van alles zullen aanwenden om de vrouw dwars te zitten en macht over haar uit te oefenen. 
noodzakelijk dat de wetswijziging gepaard gaat met een programma van maatregelen. Dit betekent bijvoorbeeld dat er een begeleidende richtlijn moet komen voor politie en justitie, waar een specifieke aanpak voor relationeel geweld in wordt vastgelegd. Als de politie een melding van relationeel geweld binnenkrijgt is een adequate reactie, gericht op het stoppen van geweld, van groot belang. Het strafrecht moet worden ingezet als interventierecht, en niet als sanctierecht. $^{23}$ Strafbaarstelling in een bijzondere wet sluit wellicht beter aan bij het strafrecht als interventierecht.

In het zoeken naar een adequate justitiële reactie kan worden aangesloten bij de ontwikkelingen op het gebied van semiformele conflictbeslechting en alternatieve straffen, zoals het ontwikkelen van specifieke leerstraffen en het ontwikkelen van daderhulpverlening voor deze groep. Hier zou de reclassering een rol in kunnen spelen. Tevens is samenwerking tussen politie, openbaar ministerie, reclassering, slachtofferhulp en andere vormen van hulpverlening en eventueel kinderrechters van groot belang. Het gaat erom dat strafbaarstelling alleen recidive niet voorkomt.

23 M.S. Groenhuijsen, Stalking, strafrecht en interventierecht, $D D$, 1998, nr. 6, p. 521 526. 